\title{
TRIAGEM AUDITIVA NEONATAL: DAS ALTERAÇÕES AUDITIVAS À ANÁLISE MOLECULAR
}

\author{
Newborn Hearing Screening: \\ From Audiological Alterations to Molecular Analyses \\ Jaqueline Medeiros de Mello ${ }^{(1)}$, Ana Maria Silveira Machado de Moraes (2), \\ Jeferson Cedaro de Mendonça ${ }^{(3)}$, Daniela Álvares da Silva ${ }^{(4)}$, \\ Laise Adriane Hegeto ${ }^{(5)}$, Valter Augusto Della-Rosa ${ }^{(6)}$
}

\begin{abstract}
RESUMO
Objetivo: verificar a prevalência da deficiência auditiva em um programa de triagem auditiva neonatal e investigar mutações do gene GJB2 naqueles com suspeita de deficiência auditiva. Método: foi realizado estudo longitudinal com $908 \mathrm{RN}$ a termo, pós-termo e pré-termo que foram submetidos à realização da triagem auditiva por meio do teste de Emissão Otoacústica Evocada por Estímulo Transiente (EOA-T) e reflexo cócleo-palpebral (RCP). Para os recém-nascidos, em que houve falha na triagem auditiva em uma ou ambas as orelhas, eram encaminhados para uma segunda avaliação. No reteste, quando o teste de EOA-T resultasse em não passa em uma ou ambas as orelhas, a criança era encaminhada para avaliação e conduta otorrinolaringológica. Após realização do Potencial Evocado Auditivo de Tronco Encefálico (PEATE) a equipe de avaliadores decidia se deveria encaminhar a criança para investigação da mutação. Quando havia suspeita de deficiência auditiva era colhido 3 $\mathrm{mL}$ de sangue venoso periférico para a pesquisa de mutação do gene da conexina 26. Resultados: foi constatado a presença de deficiência auditiva condutiva em 2 recém-nascidos $(0,22 \%)$ e neurossensorial em $1(0,11 \%)$. Na criança com deficiência auditiva neurossensorial foi detectada a presença da mutação 35delG. Conclusão: a avaliação audiológica em conjunto com exames moleculares das principais mutações do gene GJB2 em recém-nascidos com suspeita da deficiência auditiva contribuiu para a rapidez do diagnóstico audiológico, visando uma intervenção precoce, aconselhamento genético e prognóstico educacional da criança.
\end{abstract}

DESCRITORES: Triagem Neonatal; Perda Auditiva; Recém-nascido; Testes Auditivos; Mutação

\section{INTRODUÇÃO}

A deficiência auditiva (DA) acarreta sérios problemas no desenvolvimento cognitivo, social,

(1) Fonoaudióloga; Docente do curso de Fonoaudiologia da Faculdade Ingá - UNINGÁ, Maringá-PR; Doutoranda em Ciências da Reabilitação - Comunicação Humana pela Universidade de São Paulo - USP.

2) Pediatra e Geneticista Clínica; Docente do Departamento de Medicina da Universidade Estadual de Maringá - UEM, Maringá, PR; Doutora em Ciências Médicas, na Área de Genética Médica, pela Universidade Estadual de Campinas - UNICAMP, Campinas, SP.

(3) Otorrinolaringologista; Docente do Departamento de Medicina da Universidade Estadual de Maringá - UEM, Maringá-PR; Doutor em Medicina pela Faculdade de Ciências Médicas da Santa Casa de São Paulo, São Paulo, SP. intelectual e da linguagem. Este artigo permite contribuir para a epidemiologia da DA, estudando a prevalência em um programa de triagem auditiva neonatal. Alguns estudos citados ao longo deste artigo que contribuíram para a epidemiologia da DA, ora tratam da incidência, ora tratam da prevalência, entretanto possuem significados diferentes. A prevalência

(4) Médica residente em Pediatria no Hospital Universitário de Maringá (HUM), Maringá, PR.

(5) Acadêmica do 5ำ ano do Curso de Ciências Biológicas da Universidade Estadual de Maringá - UEM, Maringá,PR.

(6) Biomédico; Docente na área de Genética da Universidade Estadual de Maringá - UEM, Maringá, PR; Doutor em Ciências Biológicas e Genética pela Universidade de São Paulo - USP.

Conflito de interesses: inexistente 
representa a proporção de indivíduos que apresentam uma determinada doença, sintoma ou característica individual no momento da avaliação ou em um período estabelecido ${ }^{2-6}$. A incidência é calculada por meio de estudos populacionais com resultado de novos casos em um determinado espaço de tempo ${ }^{5,6}$.

Infelizmente, a incidência apresenta-se bastante elevada, principalmente quando comparada a doenças de alta prevalência após o nascimento, como por exemplo, a fenilcetonúria. Qualquer recém-nascido ( $R N$ ) pode apresentar problema auditivo ao nascimento ou adquiri-lo nos primeiros anos de vida, mesmo quando não haja caso de DA na família e/ou fatores de risco ${ }^{1}$.

$\mathrm{Na}$ tentativa de eliminar os efeitos negativos de DA, reside a importância do diagnóstico precoce e uma estratégia capaz de atingir tal objetivo é triagem auditiva neonatal (TAN). Tal estratégia compreende a avaliação auditiva de todos os RN, com ou sem risco para a DA, indicada no período de 24 a 48 horas de vida, para separar os $\mathrm{RN}$ que apresentam audição normal daqueles que apresentam suspeita de $\mathrm{DA}^{2}$.

A Organização Mundial de Saúde (OMS) apontou que $1,5 \%$ da população brasileira é portadora de algum tipo de DA, estando em terceiro lugar entre as deficiências do país; tal índice é ainda mais alarmante quando se trata de RN mantidos em Unidade de Terapia Intensiva Neonatal (UTI-Neo), entre os quais se estima a prevalência de 2 a $4 \%$ com comprometimento da função auditiva ${ }^{3}$.

De acordo com o censo da Fundação Instituto Brasileiro de Geografia e Estatística (IBGE) existem no Brasil cerca de 5, 735 milhões de deficientes auditivos, dos quais 166.365 apresentam incapacidade de ouvir (formas clinicamente grave do defeito). No Estado do Paraná são 312.475 deficientes auditivos, dos quais 9.038 com incapacidade de ouvir. Na cidade de Maringá o número de pessoas com alguma ou grande dificuldade de ouvir é de 8.742 pessoas 4 .

A DA é o defeito mais comum presente ao nascimento e o distúrbio neurossensorial mais prevalente em países desenvolvidos. Um em cada 500 Recém Nascidos (RN) tem DA neurossensorial permanente, maior ou igual a $40 \mathrm{~dB}$, antes dos 5 anos, a prevalência aumenta para 2,7 por $1.000 \mathrm{e}$ na adolescência para 3,5 por $1.000^{5}$. A incidência e a prevalência da DA varia nos diferentes continentes e países estando intimamente relacionadas, de maneira inversa, em nível de desenvolvimento econômico e médico-sanitário. Em países subdesenvolvidos ou em desenvolvimento, devido à alta prevalência de fatores ambientais causadores da DA, essas cifras são de três a quatro vezes superiores à detectada em países tidos como desenvolvidos. No Brasil, não há dados oficiais acerca da prevalência da DA, variando de 2 a 7 por 1.000, dependendo da região ${ }^{6}$.

As causas de DA pré-lingual, maiores ou iguais a $40 \mathrm{~dB}$, em crianças, são atribuíveis a etiologia idiopática (25\%); não genéticas (25\%) e genéticas (50\%), sendo que destas; $70 \%$ podem manifestar-se isoladamente, sendo denominada de DA não sindrômica e $30 \%$ dos casos podem estar associados a outras anomalias, constituindo a DA sindrômica. A DA não sindrômica pode ser decorrente de herança autossômica recessiva ( $75 \%$ a $85 \%)$, herança autossômica dominante (15\% a $24 \%$ ) e herança ligada ao $X$ (1\% a $2 \%$ ) e por herança materna ou mitocondrial ${ }^{7}$. Ainda para Smith e Van Camp ${ }^{7}, 50 \%$ dos casos de surdez autossômica recessiva podem ser atribuídos a mutações no loco DFNB1 (13q11-q12) e o restante aos outros locos autossômicos recessivos.

O loco DFNB1 contém dois genes associados com a DA, o gene GJB2 codificando a conexina 26 (OMIM 12011) e o GJB6 codificando a conexina 30 (OMIM 604418). Conexinas são proteínas de junção que agem na comunicação intercelular e permitem a troca rápida e passiva de pequenas moléculas entre células adjacentes, sendo também denominadas de junções do tipo gap. Essas proteínas realizam papel crucial na função fisiológica relacionada à homeostase iônica coclear e no processo endococlear. Mutações no gene responsável pela síntese da conexina 26 modificam a estrutura e funcionamento das junções gap, levando à manutenção de altas concentrações de potássio intracelular que ocasiona intoxicação das células do órgão espiral, resultando em DA ${ }^{8,9}$.

Mutações no GJB2 são as mais freqüentes causas de DA de Herança Autossômica Recessiva (HAR) não sindrômica na maioria da população mundial e de algumas populações regionais com cerca de $50 \%$ dos casos de DA de HAR ${ }^{10}$. Já foram descritas mais de cem mutações no gene GJB2 da Cx26, tendo a maioria delas expressão na cóclea. Os tipos e as freqüências das mutações são fortemente influenciados pela composição étnica da população ${ }^{11}$.

Tem-se verificado diferentes freqüências da mutação 35delG do gene GJB2 em diferentes populações. No Brasil estima que a incidência de DA devido a homozigosidade deve ser de 1 para $22.300^{6,12}$.

Diante do exposto, o presente estudo teve como objetivo verificar a prevalência da deficiência auditiva em um programa de triagem auditiva neonatal e investigar mutações do gene da conexina 26 (GJB2) naqueles com suspeita de DA. 


\section{MÉTODO}

Foi realizado um estudo descritivo que ambicionou estimar parâmetros de uma população submetida a TAN, constituída de recém-nascidos (RN) no período de maio de 2007 a dezembro de 2008.

A população de referência para o presente estudo foi constituída por $908 \mathrm{RN}$ a termo, póstermo e pré-termo nascidos no Hospital Regional Universitário da Universidade Estadual de Maringá (HUM), bem como RN atendidos na UTI-Neo provindos de outra unidade de saúde, uma vez que

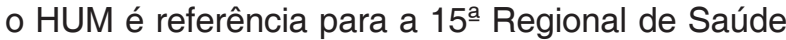
do Estado do Paraná.

Todos os RN, após a concordância da mãe e do preenchimento do Termo de Consentimento Livre e Esclarecido, foram submetidos a realização do primeiro teste de Emissão Otoacústica Evocada por Estímulo Transiente (EOA-T) e reflexo cócleo-palpebral $(\mathrm{RCP})$. Neste momento, era fornecido à mãe do $\mathrm{RN}$ o resultado da TAN de forma verbal. Se o resultado fosse positivo para a TAN era fornecida alta ao RN, e a mãe orientada de maneira simples e breve sobre os resultados dos exames, anatomia e fisiologia da audição. Também era orientada quanto ao desenvolvimento auditivo, posição da amamentação e desenvolvimento da linguagem. Para aqueles em que o teste de EOA-T resultasse em não-passa em uma ou ambas as orelhas, eram encaminhados para uma segunda avaliação (primeiro reteste) trinta dias após o primeiro teste, enfatizando a importância do retorno para os pais e/ou responsáveis.

Na segunda avaliação (primeiro reteste) quando o teste de EOA-T resultasse em não passa em uma ou ambas as orelhas, a criança era encaminhada para avaliação pelo otorrinolaringologista (ORL) para investigação de condições patológicas na orelha média. Se nesta avaliação a criança apresentasse sinal de comprometimento condutivo, a mesma era encaminhada para tratamento e posteriormente, reavaliada por meio da EOA-T. No caso de apresentar resultado de passa na TAN nessa nova avaliação era fornecida alta e orientação para os pais e/ou responsáveis. Nos casos em que o ORL não verificava indícios de comprometimento condutivo, bem como ausência de queixas e história de alterações pregressas condutiva, a conduta era encaminhar para o exame de Potencial Evocado Auditivo de Tronco Encefálico (PEATE).

Após realização do PEATE, a equipe de avaliadores (médicos e fonoaudióloga) decidia se deveria encaminhar o RN para investigação da mutação. Quando havia suspeita de DA era colhido $3 \mathrm{~mL}$ de sangue venoso periférico para a pesquisa de mutação do gene da conexina 26. Para a investigação da mutação 35delG foi empregada a técnica de PCR (Polymerase Chain Reaction) utilizando os primers GCX26 U 5'- ggTgAggTTgTgTAAgAgTTgg - 3' e GCX26 L 5'- CTggTggAgTgTTTgTTCCCAC - 3' seguido pela análise de RFLPs utilizando a enzima de restrição BSLI (BioLabs) (PENA, S.D. - personal comunication). Para a investigação da mutação 167 delT foi empregada a técnica de PCR utilizando os primers 1F 5'- GTGTTGTGTGCATTCGTCTTTTC - 3' e 3R 5'- ACCTTCTGGGTTTTGATCTCCTC - 3' seguida pela análise de RFLP utilizando a enzima de restrição Pstl (Invitrogen) ${ }^{13}$.

O protocolo do presente estudo foi aprovado pelo Comitê Permanente de Ética em Pesquisa com Seres Humanos da Universidade Estadual de Maringá CAAE no 0256.0.093.000-06.

Os dados foram analisados quantitativamente, considerando-se a distribuição estatística numérica e percentual da amostra.

\section{RESULTADOS}

No período do estudo nasceram no HUM 1.081 crianças, sendo 908 submetidas à TAN, o que representou um índice de cobertura do Programa de Triagem Auditiva Neonatal (PTAN) de $84 \%$. Dos RN avaliados, $14,2 \%(n=129)$ eram provenientes da UTI e o restante do alojamento conjunto.

Dentre $908 \mathrm{RN}$ avaliados, 460 eram do gênero feminino (50,7\%); $447(49,2 \%)$ masculino e um $(0,1 \%)$ RN não foi informado o gênero. Desses, 633 obtiveram presença de EOA-T em ambas as orelhas e, portanto, receberam alta. Entretanto, 275 obtiveram resultado de falha de EOA-T unilateral e/ou bilateral, sendo encaminhados para o reteste 30 dias após o nascimento. Destes, 182 (20\%) RN receberam alta, $62(6,8 \%)$ faltaram no reteste e $31(3,4 \%)$ foram encaminhados para avaliação e conduta com ORL (Figura 1).

Dos $31 \mathrm{RN}$ avaliados pelo ORL que falharam na TAN, 17 (55\%) apresentaram alteração otoscópica e 14 (45\%) obtiveram achados otoscópicos normais. Dentre os 17 RN com alteração otoscópica, após avaliação e conduta otorrinolaringológica, 12 (71\%) receberam alta, $3(18 \%) \mathrm{RN}$ continuaram em tratamento e $2(11 \%)$ RN não voltaram para completar avaliação após tratamento. Entre os $14 \mathrm{RN}$ com otoscopia normal, após conduta do ORL, 11 (79\%) receberam alta, em 1 (7\%) RN foi diagnosticado DA neurossensorial, em 1 (7\%) RN suspeitou de alteração retrococlear, porém não foi possível acompanhar a evolução deste, pois a mãe não retornou para conclusão do diagnóstico; e em 1 (7\%) RN não voltou para completar avaliação após encaminhamento para processo diagnóstico. 


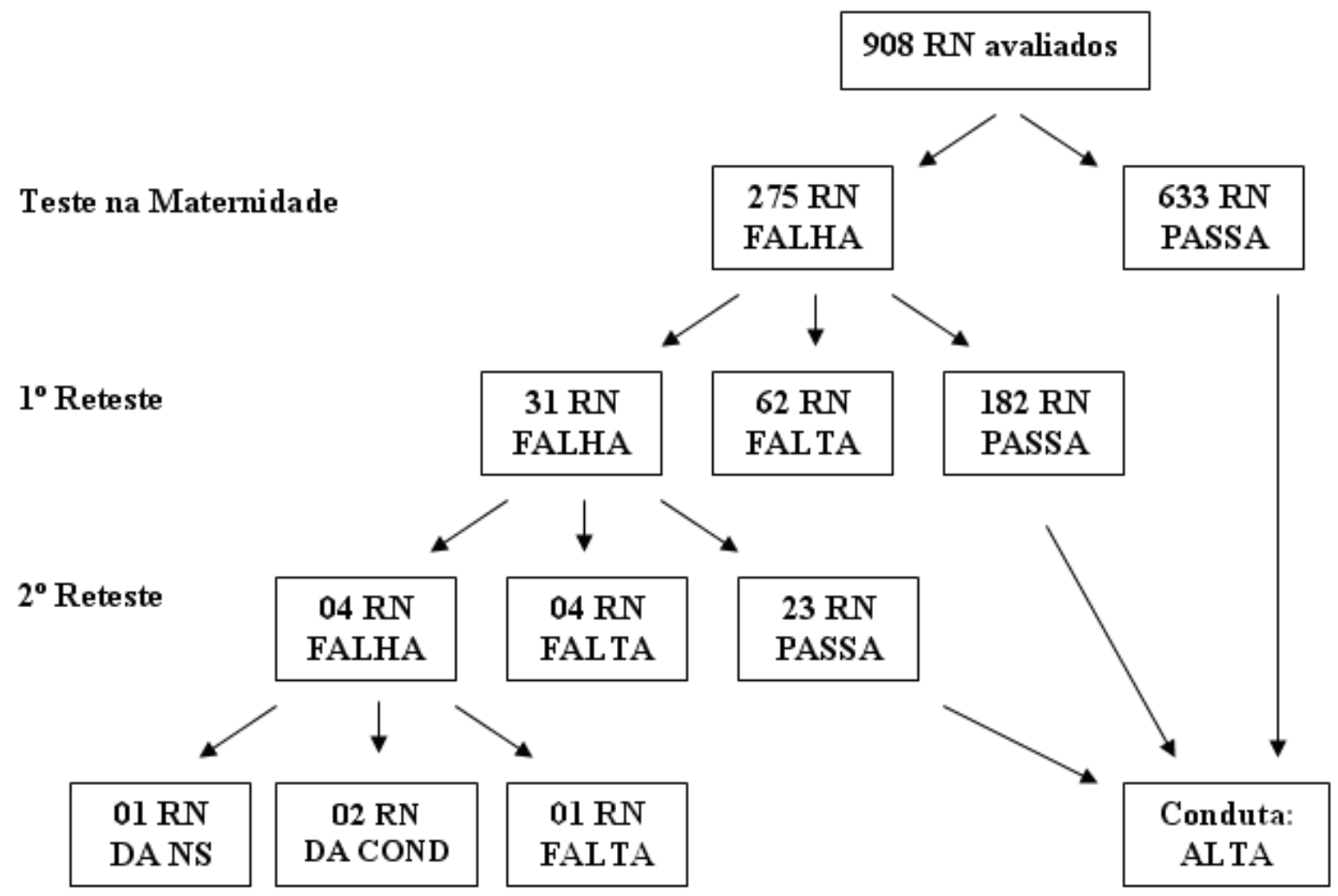

Figura 1 - Condutas de avaliações dos RN submetidos a TAN no período de maio de 2007 a dezembro de 2008 no Hospital Universitário Regional de Maringá

Após concluída a etapa de diagnóstico, foi confirmada a presença de DA condutiva em dois $(0,22 \%)$ RN e em $1(0,11 \%)$ a presença de DA neurossensorial.

Ao longo do PTAN, suspeitou-se de DA em 6 $\mathrm{RN}$, que foram encaminhados para pesquisa das mutações 35 delG e 167 del $T$ do gene da conexina 26 , sendo constatado presença de um caso em homozigose da mutação $35 \mathrm{del}$. Portanto a prevalência da DA neurossensorial neste estudo foi de 1:908.

\section{DISCUSSÃO}

O índice de cobertura do PTAN foi de $84 \%$; portanto, o caráter de universalidade do PTAN não foi alcançado, ou seja, a cobertura de $95 \%$ dos RN do hospital, como preconizado pelo Joint Committee On Infant Hearing $(\mathrm{JClH})^{14}$. Por ser um programa em fase de implantação, ocorreram alguns problemas que foram sendo sanados no decorrer do tempo, porém tais dificuldades podem ter contribuído para a não universalidade do PTAN. Alguns destes fatores foram falta de experiência dos avaliadores no início do estudo; aos domingos não era realizada a TAN por falta de avaliadores; na fase inicial do estudo, não foi realizada a TAN na enfermaria pediátrica, onde permaneciam os RN oriundos da UTI neonatal assim como não foi possível avaliar os RN ainda internados na UTI-Neo; e, por último, contribuiu a falta de comunicação entre os avaliadores e outros profissionais atuantes na maternidade.

Dos $17 \mathrm{RN}$ que foram encaminhados para avaliação com ORL com alteração otoscópica, 13 RN apresentaram achados como cêra parcial e/ ou total obstruindo o MAE, descamação do MAE e algumas vezes recobrindo a membrana timpânica (MT), otite externa, otite média secretora (OMS), MT sem translucidez e obstrução nasal. Nestes casos, os RN recebiam tratamento ou então, eram acompanhados a evolução destes quadros pelo ORL. Os achados otoscópicos alterados encontrados justificaram a ausência de EOA e a ausência de queixa de perda auditiva dos pais permitiu descartar a suspeita de DA permanente. A elevada incidência de alterações otoscópicas mostra a importância em um PTAN estar associado um profissional ORL, pois permite que a avaliação imediata do ORL descarte o encaminhamento para diagnóstico audiológico, diminuindo a angústia dos pais. Em 4 RN que apresentaram alteração otoscópica e; que foram encaminhados para o exame de 
PEATE, houve preocupação por parte da equipe de investigar condições patológicas na orelha média, pois uma tinha malformação de orelha externa, duas exibiam fissura palatina e uma com síndrome de Down, sendo solicitado o exame de PEATE e tomografia computadorizada do osso temporal para melhor investigação de anomalias crânio-faciais no caso de malformação.

Dos $31 \mathrm{RN}$ que foram encaminhados para avaliação com ORL, 8 obtiveram a confirmação do ORL de otoscopia normal, embora houvesse a dúvida dos pais com relação à audição dos filhos. Nestes casos, o ORL solicitava o exame de PEATE. Se tivesse sido possível a combinação de EOA e PEATE em nosso programa de triagem, reduziria o número de encaminhamentos para diagnóstico, pois pode ser aplicada aos RN que falham na TAN por EOA e necessitam de um exame complementar como PEATE no mesmo momento, entretanto o hospital não conta com equipamento de PEATE ${ }^{15,16}$.

Os exames de PEATE e as EOA complementam-se no momento do diagnóstico audiológico. A utilização do registro das EOA e do PEATE em diferentes etapas tem demonstrado efeito positivo e pode reduzir significativamente o número de RN encaminhados para diagnóstico audiológico ${ }^{17}$.

Do total de $31 \mathrm{RN}$ encaminhados para avaliação com ORL, um recebeu a conduta do ORL de suspeita de alteração retrococlear, devido à ausência de RCP e presença de EOA. Neste caso, anterior ao encaminhamento para o ORL, o ideal seria a realização do PEATE, entretanto, como já mencionado o equipamento de PEATE não era disponível no HUM.

Um dos vilões da TAN utilizando apenas o registro de EOA é a presença de alterações em nível neural ${ }^{18}$. Já que a TAN por meio do exame de EOA é um procedimento eficiente na identificação de DA de origem periférica somente ${ }^{19}$. Por isto, a recomendação é associar o RCP às EOA para então detectar todos os tipos de DA, uma vez que o RCP pode estar ausente na DA retrococlear, por alteração na transmissão neural ${ }^{20}$. Entretanto, deve-se ressaltar que o RCP apresenta sensibilidade de $75 \%$ e especificidade de $78,7 \%{ }^{18}$.

Handa ${ }^{21}$ complementou que a TAN por meio das EOA não é um procedimento eficaz para a detecção das alterações retrococleares; a pesquisa do RCP é um procedimento que pode ser utilizado na identificação destas alterações, porém, por si só, não é um método eficiente; e a TAN por EOA e RCP pode ser utilizada na identificação de alterações retrococleares, porém, ainda não é um procedimento totalmente eficaz. Mesmo assim, a associação entre ambos aumenta a sensibilidade na identificação de tais alterações.

A ocorrência de DA retrococlear é maior na população que apresenta indicador de risco para a deficiência auditiva. Neste caso, o Comitê Multiprofissional em Saúde Auditiva (COMUSA) ${ }^{17}$ que agrega estudos nacionais na área de Fonoaudiologia, Otologia, Otorrinolaringologia e Pediatria recomenda a utilização do PEATE, pois alterações retrococleares como a neuropatia auditiva não podem ser identificadas quando se utiliza apenas o registro das EOA. Após a conduta do ORL de tratamento das alterações condutivas, acompanhamento de alguns casos, retorno dos $\mathrm{RN}$ com resultado de PEATE, encaminhamento para pesquisa da mutação genética e realização de novos retestes no ambulatório de pediatria do HUM, foi fornecido alta a $23(74,2 \%)$ RN, 4 (12,9\%) foram perdidos por não obter contato e $4(12,9 \%)$ continuaram apresentando falha no registro de EOA.

Dos $4(12,9 \%)$ que continuaram apresentando falha no registro de EOA, um foi confirmada a DA neurossensorial, em um não foi possível estabelecer o diagnóstico, e em dois houve continuidade do tratamento devido a presença de DA condutiva. Portanto, no presente estudo, foi confirmada presença de DA condutiva em $2(9,52 \%) \mathrm{RN}$ e em $1(0,11 \%) \mathrm{RN}$ a presença de DA neurossensorial.

A prevalência de DA condutiva foi maior que a DA neurossensorial o que é compreensível, pois o diagnóstico de DA condutiva é a alteração mais comum nos PTAN ${ }^{20}$ Garcia, Isaac e Oliveira ${ }^{21}$ encontraram índices de 10,4 a 47,6 RN para 1000 sugestivos de DA condutiva em seus estudos.

Referente à DA neurossensorial, os achados do presente estudo confirmam a prevalência de DA que varia de 1 a 2 RN com DA para cada 1.000 nascimentos e a estimativa de 1 a $3 \mathrm{RN}$ em cada 1.000 nascimentos ${ }^{16}$.

A prevalência de DA neurossensorial encontrada em alguns estudos nacionais e internacionais foi de 5:4.196 RN, ou seja, $0,1 \%{ }^{22} ; 1: 346$ RN com incidência de $0,3 \%{ }^{23} ; 1: 1.127 \mathrm{RN}(0,08 \%)$ 24; 2,3:1000, ou seja, $0,23 \%{ }^{25} ; 10: 4.631$ com incidência de $0,2 \%$ 22; 4:3.371 RN $(0,1 \%)^{21}$; 2 a 29,9:1000 para DANS $(0,2 \text { a } 3 \%)^{26} ; 3,6: 21.834$ RN $(0,02 \%)^{25}$. Todavia em todos os estudos, alguns fatores devem ser considerados, como o tamanho da amostra; diferença na idade gestacional; relação com o estado clínico estável dos RN e presença ou não de IRDA.

Referente ao encaminhamento para pesquisa da mutação no gene GJB2, $6(0,66 \%)$ do total da amostra foram encaminhados para o teste molecular, sendo constatado presença em homozigose da mutação 35 delG no gene GJB2 em um $(0,11 \%)$ RN do total da amostra. Entretanto, o COMUSA ${ }^{17}$ 
recomenda a inclusão da triagem genética somente após a confirmação do diagnóstico da DA, devido à necessidade de se investigar o custo, a efetividade, e a viabilidade do estudo genético, na maternidade. Apesar de reconhecimento da importância das DA congênita de origem genética, principalmente no que se refere à conexina $26{ }^{17}$.

É consenso atual que as mutações no loco DFNB1 sejam claramente a causa mais comum de DA em muitas populações. No Brasil, investigou-se a prevalência da mutação do $35 \mathrm{del}$ G em uma população de $223 \mathrm{RN}$, na qual encontraram uma prevalência de $2,24 \%$ de portadores dessa mutação ${ }^{27}$, contra $0,11 \%$ no presente estudo.

Assim, mesmo em um universo reduzido de 6 RN com suspeita de DA, estes dados confirmam a importância da investigação da mutação 35delG em RN com suspeita de DA, pois antes mesmo do fechamento do diagnóstico audiológico, já se sabia da presença da DA neurossensorial pela presença de mutação na triagem genética. Por isto, existe relativa facilidade no diagnóstico genético pela testagem da conexina 26 que permite a identificação precoce de crianças com DA causada por mutações no GJB2. A triagem genética realizada em conjunto com os exames de EOA e PEATE leva a um aconselhamento médico, audiológico, genético e educacional precoce para a criança e familiares ${ }^{28}$.

$\mathrm{Na}$ criança portadora de DA neurossensorial com a mutação 35delG em homozigose foi possível alcançar o diagnóstico precoce. Os indivíduos com DA congênita, de origem genética, geralmente não apresentam malformações do sistema auditivo, o que favorece o uso de implante coclear ${ }^{29}$. Embora, na criança em questão foi realizada a adaptação do Aparelho de Amplificação Sonora Individual (AASI), visando minimizar o impacto negativo causado pela DA na aquisição da fala e linguagem, no desempenho acadêmico e no desenvolvimento sócio-emocional.

\section{CONCLUSÃO}

Este estudo mostrou que a prevalência da DA condutiva foi maior que a DA neurossensorial, mostrando similaridade com estudos nacionais e internacionais. A importância da investigação da análise molecular associado a TAN especialmente das mutações do genes 35delG do gene GJB2 do loco DFNB1.

A avaliação audiológica em conjunto com exames moleculares das principais mutações do gene GJB2 (35delG e 167delT) em RN com suspeita de DA contribuiu para a rapidez do diagnóstico audiológico, visando uma intervenção precoce, aconseIhamento genético e prognóstico educacional da criança afetada.

\section{AGRADECIMENTOS}

Ao fomento do CNPQ e MS-SCTIE-DECIT, acadêmicos do curso de Fonoaudiologia da UNINGÁ, acadêmicos do curso de Medicina da UEM, Hospital Universitário de Maringá (HUM) e Mirian Fernandes Martins - assistente social do HUM.

\begin{abstract}
Purpose: to assess the prevalence of hearing loss in a newborn hearing screening program and investigate mutations in the GJB2 gene in those with suspected hearing loss. Method: we performed longitudinal study of 908 term infants, post-term and preterm infants who underwent hearing screening by the test Emission Transient Evoked Otoacoustic (EOA-T) and cochlear palpebral reflex. For newborns, those who failed the hearing screening in one or both ears, were referred to a second evaluation. In the retest, while the EOA-T test result in not passing on one or both ears, the child was referred for evaluation and otorhinolaringology management. After completing the Auditory Evoked Potential test, the team of evaluators decided whether it should refer the child to investigate the mutation. When there was suspicion of hearing impairment we collected $3 \mathrm{~mL}$ of peripheral venous blood for the detection of mutation in the connexin 26 gene. Results: we observed the presence of conductive hearing loss in 2 neonates $(0.22 \%)$ and sensorineural in $1(0.11 \%)$. In children with sensorineural hearing loss we detected the presence of $35 \mathrm{delG}$ mutation. Conclusion: the audiological assessment in conjunction with molecular tests of the main GJB2 gene mutations in newborns with suspected hearing loss contributed to the rapid audiological diagnostic, seeking early intervention, educational and genetic counseling and prognosis of the child.
\end{abstract}

KEYWORDS: Neonatal Screening; Hearing Loss; Newborn; Hearing Tests; Mutation 


\section{REFERÊNCIAS}

1. Hilú MRPB, Zeigelboim BS. O conhecimento, a valorização da triagem auditiva neonatal e a intervenção precoce da perda auditiva. Rev. CEFAC [online]. 2007; 9: 563-70. Acesso em março de 2009. Disponível em: http://www.scielo.br/pdf/ rcefac/v9n4/15.pdf

2. Nielsen CB, Neto HAF, Gattaz G. Processo de implantação de Programa de Saúde Auditiva em duas maternidades públicas. Rev Soc Bras Fonoaudiol. 2007; 12: 99-105.

3. Gatto $\mathrm{Cl}$, Tochetto TM. Deficiência auditiva infantil: implicações e soluções. Rev. CEFAC [periódico na internet]. 2007, 9(1):110-5. Acesso em março de 2009. Disponível em: <http://www. scielo.br/scielo.php?script=sci_arttext\&pid= S1516-18462007000100014\&lng=pt\&nrm=iso>.

4. Fundação Instituto Brasileiro de Geografia e Estatística (IBGE) - Censo Demográfico 2000 Características gerais da população. Resultados da amostra disponível em http://www.ibge.gov.br/ censo acesso em 15 de julho de 2006.

5. Morton CC, Nance WE. Newborn hearing screening-a silent revolution. N. Engl J Med. 2006; 354: 2151-64.

6. Oliveira CA, Pimpinati CJ, Alexandrino $F$, Magna LA, Maciel-Guerra AT, Sartorato EL. Allelic frequencies of the 35delG mutation of the GJB2 gene in different brazilian regions. Gen Test. 2007; 11: 1-3.

7. Smith, RJH, Van Camp, G. Deafness and hereditary hearing loss overview. In: Pago RA, Bird RC, Dolan CR, Stephens K. GeneReviews (Internet) in University of Whashington, Seatle updated 2008. Disponível em: http://www.ncbi.nlm.gov/bookshelf/ br.fcgi?book=gne\&part=deafness-overview. Acesso em: 01 de agosto de 2010.

8. Lefebvre PP, Van Den Water TR. Connexins, hearing and deafness: clinical aspects of mutations in the connexin 26 gene. Brain Res Rev. 2000; 32: 159-62.

9. Shibata Y, Kumai M, Nishi K, Nakamura K. Diversity and molecular anatomy of gap junctions. Med Electron Microsc 2001; 34:153-9.

10. Keneson, A., Van Naarden Braun, K., Boyle, C.,. GJB2 (connexin 26) variant and non-syndromic sensorineural hearing loss: a HuGe review. Genet Med, 2002; 4: 258-74.

11. Batissoco AC, Abreu-Silva, RS, Braga MCC, Lezirovitz K, Della-Rosa V, Alfredo Jr T, Otto PA, Mingroni-Neto RC. Prevalende of GJB2 (connexin-26) and GJB6 (connexin-30) mutations in a cohort of 300 brazilian hearing-impaired individuals: implications for diagnosis and genetic counseling. Ear \& Hearing. 2009; 30: 1-7.
12. Oliveira CA, Alexandrino F, Christiani TV, Steiner CE, Cunha JLR, Guerra ATM, Sartorato EL. Molecular genetics study of deafness in Brazil: 8-year experience. American Journal of Medical Genetics, 2007; 14: 1574-9.

13. Robin NH; Prucka SK; Woolley AL; Smith $\mathrm{RJH}$. The use of genetic testing in the evaluation of hearing impairment in a child. Current Opinion in Pediatrics. 2006; 17: 709-12.

14. Joint Committee on Infant Hearing. Year 2007. Position Statement: principles and guideslines for early hearing detection and intervention programs. Pediatrics. 2007; 20: 898-921.

15. Grill E, Uus K, Hessel F, Davies L, Taylor RS, Wasem J. Neonatal hearing screening: modeling cost and effectiveness of hospital and communitybased screening. BMC Health Serv Res. 2006; 6:14. 16. Grupo de Triagem Auditiva Neonatal Universal (GATANU). Disponível em www.gatanu.org/tan/ introducaoTAN.php. Acesso em 01 de abril de 2009. 17. Comitê Multiprofissional em Saúde Auditiva (COMUSA), 2009. Disponível em: http://www. audiologiabrasil.org.br/pdf/COMUSA_final_17_ maio2009.pdf. Acesso em julho de 2009.

18. Simonek MCS, Azevedo MF. Respostas falsopositivas na triagem auditiva neonatal universal: possíveis causas. Rev. CEFAC. [online] ahead off print . 2010. Acesso em julho de 2010. Disponínel em: $\quad<$ http://www.scielo.br/scielo.php?script=sci arttext\&pid=S1516-18462010005000076\&lng=pt\&n rm=iso>

19. Garcia CFD, Isaac ML, Oliveira JAA. Emissão otoacústica evocada transitória: instrumento para detecção precoce de alterações auditivas em recém-nascidos a termo e pré-termo. Rev Bras Otorrinol 2002; 68: 344-52

20. Pereira PKS, Azevedo MF, Testa JR. Alterações condutivas em neonatos que falharam na triagem auditiva neonatal. Braz. J. Otorhinolaryngol. [online]. 2010; 76: 347-54. Acesso em julho de 2010. Disponível em: http://www.scielo.br/pdf/bjorl/ v76n3/v76n3a13.pdf

21. Handa PR. Triagem auditiva neonatal: correlação com a avaliação audiológica no final do primeiro ano de vida (Monografia). São Paulo: Universidade Federal de São Paulo; 2002.

22. Chapchap MJ, Segre CM. Universal newborn hearing screening and transient evoked otoacoustic emission: new concepts in Brazil. Scand Audiol. 2001; 30: 33-6.

23. Roth DAE, Hildesheimer M, Maayan-Metzger A, Muchnik C, Hamburger A, Mazkeret R, Kuint J. Low prevalence of hearing impairment among very low birthweight infants as detect by universal neonatal hearing screening. Arch Dis Child Fetal Neonatal. 2006; 91: 257-62. 
24. Borges CAB, Moreira LMO, Pena GM, Fernandes $\mathrm{FR}$, Borges BCB, Otani BH. Triagem Auditiva Neonatal Universal. Arq. Int. Otorrinolaringol. 2006; 10: 28-34.

25. Khandekar R. Neonatal screening for hearing impairment - The Oman experience. Int $\mathrm{J}$ Pediatr Otorhinolaryngol. 2006; 70: 663-70.

26. Jardim IS, Matas CG, Carvallo RMM. Emissões Otoacústicas Evocadas por estímulos transientes e potenciais auditivos de tronco encefálico automático na triagem auditiva neonatal. Einstein. 2008; 6: 253-61
27. Piatto VB, Oliveira CA, Alexandrino F, Sartorato EL. Perspectivas para triagem da deficiência auditiva genética: rastreamento da mutação $35 \mathrm{delG}$ em neonatos. J Pediatr. 2005; 81: 39-42.

28. Cohn ES, Kelley PM. Clinical phenotype and mutations in connexin 26 (DFNB1/GJB2), the most common cause of childhood hearing loss. Am J Med Genet 1999; 89: 130-6.

29. Apps SA, Rankin WA, Kurmis AP. Connexin 26 mutations in autosomal recessive deafness disorders: A review. Int J Audiol. 2007; 46: 75-81.

Endereço para correspondência:

Jaqueline Medeiros de Mello

Rua Vaz Caminha, 633

Maringá-PR

CEP: 87010-420

E-mail: jaquedemello@yahoo.com.br 